\title{
Reversibility of Polymer-Induced Fiber Flocculation by Shear. 1. Experimental Methods
}

Martin A. Hubbe, Department of Wood and Paper Science, North Carolina State University, Raleigh, NC, U.S.A.

Keywords: Retention, flocculation, flocs, formation, drainage rate, hydrodynamics

SUMMARY: Papermakers desire two seemingly incompatible outcomes. On the one hand, strong agglomeration of fibers and fines can help one to achieve rapid drainage and satisfactory fine-particle retention. On the other hand, papermakers also want uniform distribution of fibers in the sheet. Procedures have been developed in our lab to evaluate effect of different retention and drainage chemical programs under stressed conditions of salt content, fines content, or high levels of charged colloidal matter. In the work described here the same tests were used to compare the reversibility of agglomerative effects of some common classes of retention and drainage programs.

Optical and viscometric tests showed increased flocculation following treatment with increased amounts of cationic polyacrylamide. Application of intense hydrodynamic shear caused essentially complete reversal of flocculation. By contrast, treatment with a highly charge density cationic polymer yielded a maximum in flocculation, according to the optical test, at a treatment level corresponding to the point of charge neutralization.

Divergent results were obtained when comparing fine-particle retention tests to drainage tests. In general, retention results were consistent with a model in which polymer bridges, i.e. "hard flocs," between fibers may be irreversibly broken by shear. Meanwhile, bonds formed between fibers and fine particles appeared to remain intact. In contrast, drainage results appeared to be more highly dependent on the electrokinetic properties of the furnish, i.e. factors related to "soft floc" formation.

ADDRESS OF THE AUTHOR: Department of Wood and Paper Science, North Carolina State University, Box 8005, Raleigh, NC 27695-8005, U.S.A.

\section{Introduction}

Papermaking involves a complex interplay between fibers, chemical flocculating agents, and hydrodynamic shear. Papermakers use flocculants to accelerate release of water and to help in the retention of fine particles as the paper sheet is formed. On the plus side, the improved drainage and retention can be highly advantageous to the papermaker, allowing increased production and process efficiency. On the minus side, chemical flocculation of fibers can make the paper less uniform. Because of this fact, papermakers are continually involved with finding better ways to balance the benefits and penalties of flocculant use. To help this effort, this report introduces two methods that can be used to quantify the level of fiber flocculation or the strength of fiber flocs before and after hydrodynamic shear has been applied. 
The term "hard" will be used in this paper to describe strong attachment between fibers, such as those created by polyelectrolyte bridges (Britt, Unbehend 1976). Jar tests show that such flocs break down irreversibly when exposed to sufficiently high levels of hydrodynamic shear. Sikora and Stratton (1981) report that breakup of hard flocs can involve the scission of covalent bonds within the chain of a retention aid polymer.

By contrast, the term "soft" will be applied to fiber flocs that are (a) broken down by relatively low shear forces, and (b) are capable of forming again to about the same degree when the shear is removed. Kerekes (1995) reviews past theoretical and experimental work in this area, showing that residual stresses within bent fibers are often sufficient to form coherent flocs that remain intact after flow has ceased. Although high levels of hydrodynamic shear can be momentarily effective for redispersing fibers, it is usual for some soft flocs to form again quickly as the fibers bent by shear straighten themselves out (Raghem-Moayed, Kuhn 2000).

As shown by Tam Doo, Kerekes and Pelton (1984) the unit operations of a typical paper machine system provide a wide range of hydrodynamic shear environments. Certain of these unit operations such as pressure screens are very effective for breaking up fiber flocs, including hard flocs caused by retention aids. Experiments by Hubbe $(1985,1986)$ suggest that attachments between fibers and fine particles are more likely to survive exposure to shear. The ability of very small particles to remain attached to fibers exposed to shear is shown to be a consequence of colloidal forces of adhesion, geometrical considerations, and the effects of flow. In principle it is possible to employ chemical additives in combination with shear in such a way as to achieve a relatively uniform distribution of fibers in paper, while at the same time achieving increased retention efficiency.

The concept of reversibility is further developed in studies by Hedborg and Lindström (1996) and Swerin et al. (1997b). A reversibility index $\left(I_{\mathrm{R}}\right)$ is defined as a ratio of differences,

$$
I_{\mathrm{R}}=(\mathrm{B}-\mathrm{A}) /(\mathrm{C}-\mathrm{A})
$$

where $\mathrm{C}$ is the fine particle retention efficiency at a low rate of agitation before application of high shear, $\mathrm{A}$ is the fine particle retention efficiency at the high shear level, and $\mathrm{B}$ is the fine particle retention efficiency after exposure to high shear when the system is returned to a low rate of stirring. By using this definition it is found that chemical flocculant systems can vary greatly with respect to reversibility. For instance, in the case of treatment of the furnish with modified polyethyleneimine (PEI) copolymer the reversibility index is low. There is little tendency for the stock to reflocculate when low-shear conditions are restored. By contrast, a high reversibility index is observed in the case of a microparticle retention aid treatment with cationic polyacrylamide and bentonite clay.

Swerin et al. (1997b) report reflocculation of microcrystalline cellulose that had been treated with a wide range of different retention aid systems and then dispersed by hydrodynamic shear. A new finding of the cited work is that the ability of flocs to form again after being dispersed is not limited to systems coagulated by salts or high-chargedensity cationic polymers. Rather, reversibility is observed even in the case of a very 
high-mass cationic polyacrylamide (cPAM) flocculant. However, subsequent addition of colloidal silica after the cPAM yields a stronger tendency to re-floc after dispersal.

\section{Sensing the Size of Fiber Flocs}

Optical tests are found to be very useful in studies of fiber flocculation. Mason (1954) reports that fluctuations in transmitted light can be used to detect mechanical flocculation of fibers in couette flow. Friction and the bending of individual fibers are sufficient to hold fibers together in groups of four or more, even when no chemical flocculant has been employed (Andersson et al. 1999). Farnwood et al. (1993) report results from duallaser backscattering from fibers in dilute slurry coming from the slice of a paper machine headbox. The fibers are found to reflocculate within about 0.1 seconds after the cessation of shear. Such rapid reflocculation is consistent with the high length-to-width ratio of cellulosic fibers and their resulting collisions in a turbulent shear flow regime. Swerin et al. $(1993 \mathrm{a}, \mathrm{b})$ report use of a laser method to evaluate breakup and repair of flocs in fiber suspensions exposed to retention aids, followed by increased hydrodynamic shear. Greater detail, including floc size, shape, frequency, and density can be obtained by image analysis (Beghello et al. 1996; Kaji, Monna 1991).

The optical test to be described in the Experimental section of this report is related to work by Gregory (1973). Fluctuations in the intensity of light transmitted through a tube are used to sense the state of agglomeration of colloidal particles exposed to different concentrations of polyelectrolytes. By this means Gregory is able to collect the data needed to support his theory of polymer bridging, a theory which has become well accepted. Krogerus (1993) reports results with two such devices in a study of the flocculation of fiber fines or clay.

\section{Sensing the Strength of Fiber Flocs}

Information about the strength of fiber flocs can be useful in predicting whether they are likely to be dispersed during papermaking operations, or whether they will persist and hurt the uniformity of the product. Reports of the direct measurement of fiber floc strength are rare (Yeung, Pelton 1996). It is far more common to use hydrodynamic forces to evaluate forces of attachment between small, submerged objects. For instance, it is possible to evaluate the strengths of polyelectrolyte bridges in the wet state by determining the shear stress required to detach particles from fixed surfaces exposed to flow (Janex et al. 1997; Pelton, Allen 1984; Mühle 1987; Hubbe 1987).

Caution is required when using detachment-force information to predict the likelihood of fiber floc dispersal. It is found that the shear stress required to detach particles attached to a surface exposed to flow decreases as the size of the particle increases (Hubbe 1985). As noted many years ago by McKenzie (1968) destruction of fiber aggregates can be brought about by shear forces several orders of magnitude less than those required to break up fiber-additive aggregates. More detailed work is needed to examine how the relative sizes of fibers and fines affect detachment forces when fiber suspensions are exposed to different flow regimes.

Recent reports involved with fiber floc strength, based on rheometric methods, deal with such issues as yield stress (Bennington et al. 1990) and the elastic and inelastic components of floc strength (Swerin et al 1992,1993b). It is shown that treatment with retention aid chemicals can greatly increase the strength of a fiber network. An optimum 
degree of substitution of cationic flocculants is reported. In theory, a very low charge of the flocculant provides less driving force for adsorption onto the fibers, resulting in weaker bridging bonds. Conversely, a $100 \%$ substitution level of cationic charge on the polyelectrolyte limits the amount that can become adsorbed onto a cellulosic surface that typically has an anionic charge density at least a factor of ten lower.

An important industrial use of rheometric measurements of fiber suspensions is in the estimation of the solids level or "consistency." On-line consistency probes and transmitters are widely used to determine consistency values of pulp before or after refining operations (Petersen (1994). Preikschat (1998) demonstrates the use of a rotating consistency transmitter with a modified rotor with a large ratio of leading edge to blade area. By this means, the resulting signal is relatively insensitive to the presence or absence of filler in the stock. As a bonus, the signal also is almost linear with fiber solids within the consistency range of zero to $12 \%$. This makes the general approach very interesting in terms of wet-end chemistry, where it is important to obtain reproducible measurements in the range of about $0.4 \%$ to about $1.2 \%$ solids.

\section{Sensing the Consequences of Fiber Flocs}

As noted by Sampson (1997), drainage rates depend not only on freeness, but also on the structure of the fiber mat as it forms. Retention efficiency is less directly connected to productivity. Britt and Unbehend (1976) note that factors promoting drainage in the early stages of dewatering on a Fourdrinier former can impede vacuum dewatering. The phenomenon is attributed to the effects of treatments on formation of fiber flocs. Under dilute conditions the free water can flow around the flocs and drainage is promoted. Under the conditions of vacuum dewatering, air is the fluid that flows around flocs, and water tends to remain behind locally within flocs. Due to these factors it is recommended to measure both the initial drainage rate and the moisture remaining in a fiber pad after a set time of vacuum dewatering (Forsberg, Bengtsson 1990, Gess 1984). More advanced developments in this area include the use of pressure pulsations to simulate the effects of hydrofoil action during dewatering on a commercial paper machine (Lin 1994; Räisänen et al. 1994; Sweger 1996). Pressure pulsations can provide insight as to what is happening in a real paper machine system. For simplicity the present work was limited to use of a steady vacuum dewatering on a screen.

Optical tests are widely used to evaluate fines retention. Some widely used automated devices for monitoring and controlling the consistency of white water use light scattering data and control algorithms to adjusting retention aid chemical dosages (Rantala et al. 1994; Artama, Nokelainen 1997). Milliken (1977) reports the use of turbidity as a way to speed up practical evaluations carried out with the Britt Jar (Britt 1973a). The same approach has been used in the present study.

\section{Materials}

\section{Pulp Furnish}

Bleached softwood chemithermomechanical pulp (BCTMP) was obtained from Quesnel River Pulp Co. The mixture employed during the work described consisted of $80 \%$ product Q120/60 and 20\% Q400/B70. In each case the number preceding the slash indicates the nominal Canadian Standard Freeness in $\mathrm{ml}$. The ground calcium carbonate 
used was Omyafil@ from Omya, Inc. A master batch was prepared in which the fiber solids were $0.5 \%$ and the mineral solids were $0.05 \%$.

\section{Chemicals}

Polymeric additives were prepared with distilled water by diluting the following commercial products.

The cationic polyacrylamide (cPAM) was an emulsion product EKA PL® 2410 from Eka Chemicals. This cPAM product has a 10\% molar charge content and a molecular mass of 9 to 12 million Daltons. The cPAM was diluted to $0.5 \%$ of the asreceived concentration, and evaluated on an "as-received" basis.

Effects of a highly charged, high mass, linear poly-diallyldimethylammonium chloride (DADMAC) products were observed. The polyDADMAC was Alcofix ${ }^{\circledR} 109$ from Ciba Specialty Chemicals, a product with a nominal molecular weight of 1 million Daltons. The polyDADMAC was diluted to $0.1 \%$ active polymer and used on an "actives" basis.

\section{Methods}

\section{Evaluation of Floc Size or Intensity}

The relative intensity of fiber flocculation was evaluated with a newly modified version of the Photometric Dispersion Analyzer PDA 2000 (Low Gain Version) from Rank Brothers, Ltd. Previous published studies with the PDA 2000 are restricted to dispersions of particles in the colloidal size range (Gregory 1973,1985; Eisenlauer et al. 1987). Krogerus (1993) reports results from a PDA 2000 with fiber fines and kaolin clay particles. The reason for the size restriction is that the original device uses flexible, transparent tubing having an inner diameter of either $1 \mathrm{~mm}$ or $3 \mathrm{~mm}$.

Modification of the original method was necessary in order to evaluate fiber flocs, since an individual fiber may be either about $1 \mathrm{~mm}$ (hardwood) or $3 \mathrm{~mm}$ (softwood) in length. Experiments described in this report were conducted with Tygon ${ }^{\circledR}$ tubing having an inner diameter of $6.35 \mathrm{~mm}(1 / 4 \mathrm{inch})$ and an outer diameter of $9.52 \mathrm{~mm}(3 / 8 \mathrm{inch})$. At our request Rank Brothers Limited provided a newly designed holder for this type of tubing.

Floc tests were carried out with $400 \mathrm{ml}$ samples of fiber slurry that had been treated and shear-conditions according to procedures to be described at the end of this section. The slurry was stirred at the " 2.5 " setting of a Fisher brand weight-activated magnetic stirrer (Catalogue 14-505-21). As shown in Fig. 1, one end of the Tygon tubing described earlier was held approximately $6 \mathrm{~mm}$ from the bottom of the beaker. During each test slurry was drawn vertically from the beaker and through a PDA 2000 device immediately above the beaker by means of a Masterflex Easy-load model 77601-10 peristaltic pump with a $0.2 \mathrm{HP} 20-650 \mathrm{rpm}$. drive model 7592 and digital controller. The distance between the tube opening and the sensing head of the PDA 2000 was $375 \mathrm{~mm}$. The flow rate was $530 \mathrm{ml} / \mathrm{min}$. The other end of the tubing was placed just above the level of slurry in the beaker so that the slurry was recirculated with a minimum of splashing. Tests were carried out with following PDA instrument settings: Gain constants $($ both $)=1.0$; "Filter" button = depressed; and "RMS" button = depressed. 
After a settling period of 15 seconds, a series of five output values was observed and recorded.

To get a sense of how much the peristaltic pumping affected floc size, another series of PDA 2000 data was obtained in each case after 30 seconds of additional pumping.

\section{Evaluation of Floc Strength}

Determination of the strength of flocs usually involves a destructive test, changing the very thing that one wishes to measure. One of the goals in designing a new test was to minimize this effect, making it possible to separately evaluate the effects of chemical flocculants and subsequent application of hydrodynamic shear. A further goal was to be able to sense the state of flocculation at a typical fiber consistency for paper forming, e.g. $0.5 \%$ on a mass basis. Though a series of preliminary experiments it was found that the project objectives could be met by using a Brookfield digital viscometer and a specially modified probe.

As shown in Fig. 2, the probe was assembled by attaching a pair of $6.3 \mathrm{~mm}$ diameter plastic rods to opposite inner walls of the Brookfield viscometer spindle No. 1 (open-ended cylinder). By this means the pair of probes was kept parallel and vertical, with their centers spaced $50 \mathrm{~cm}$ apart. Slurry samples were placed in a cylindrical plastic beaker provided with baffles on its inner wall to prevent development of a fiber-free slip zone. The inner diameter of the cylindrical beaker was $90 \mathrm{~mm}$. Four vertical baffles made from the same $6.3 \mathrm{~mm}$ diameter plastic rods were placed symmetrically on four sides of the inner wall of the beaker. During testing the probes were immersed $50 \mathrm{~cm}$ into the slurry sample.

Measurements were conducted mainly at the $50 \mathrm{rpm}$. setting of the viscometer, using the "\%" output option. Supplementary measurements at the $20 \mathrm{rpm}$ setting were obtained in a few cases in which high levels of flocculation made the reading go off scale. At least five measurements were obtained, spaced by about 2 seconds each, and the results were averaged.

As noted later, the floc strength analysis tests were repeated before and after the first set of floc size measurements as described above.

\section{Evaluation of Retention, Drainage, and Pad Moisture}

Design goals for the drainage and retention tests used in this work included simplicity, convenience, sensitivity to chemical treatments, and an ability to sense both the drainage rate and the solids level of a fiber pad after a standard application of vacuum. Because there was no pressure pulsation employed, the results were not expected to predict paper machine operations.

Tests were conducted with $200 \mathrm{ml}$ subsamples of slurry, immediately after the evaluation of floc size and strength. The slurry was placed in a filter apparatus above a 150-mesh screen having an open diameter of $42 \mathrm{~mm}$. At time equal to zero, tests were initiated by application of a steady $50 \mathrm{kPa}$ of vacuum. The "drainage time" was identified with an abrupt change in appearance of the fibers remaining above the screen, similar to the appearance of a "dry-line" during operation of a Fourdrinier former.

After recording the drainage time, the vacuum application was continued for a net elapsed time of 30 seconds. All of the moist pulp from the filter was transferred to a 
small, tared beaker and weighed. Because the fiber solids in each sample were held constant, the wet mass provided an indication of moisture content.

Filtrate turbidity was measured using a Model DRT-100B Turbidimeter from HF Instruments.

\section{Evaluation of Electrophoretic Mobility}

Electrophoretic mobility data were obtained with an SKS Charge Analyzer, Model II from SKS Associates of North Hampton, NH. The portable instrument permits conventional capillary microelectrophoresis experiments, with a unique ability to rapidly switch from one sample to the next. This makes the equipment especially suitable for observed the progressive effects of increasing levels of charged chemicals.

\section{Sample Handling and Order of Experiments in Each Series}

Each replication of each experimental condition was started by measuring $400 \mathrm{ml}$ of slurry sample having fiber solids of $0.5 \%$ and a total solids level of $0.55 \%$ (see Materials). Each such sample was separately conditioned in a Waring blender to simplify subsequent interpretation of shear effects. The following order of sample handling and testing procedures was used in each case:

1. The $400 \mathrm{ml}$ of untreated fibrous slurry from the master batch was placed in a standard Waring Blender and agitated at the "blend" setting for 30 seconds.

2. The slurry sample was placed in a cylindrical beaker of $90 \mathrm{~mm}$ inner diameter (see Evaluation of Floc Strength) and stirred magnetically at a rate just sufficient to ensure ready mixing of chemicals.

3. A first chemical treatment (or none in the case of a blank) was added by syringe.

4. After addition of chemical (or blank), the slurry was magnetically stirred for an additional 15 seconds.

5. In case of multiple chemical treatments, each was spaced by 15 seconds with constant stirring with a 15 second period of stirring after the final chemical.

6. The stirbar was removed with a magnetic rod.

7. The floc strength was evaluated as described earlier (first such measurement).

8. The floc intensity was evaluated as described earlier (first such measurement).

9. The floc intensity was evaluated again after 30 seconds of continued peristaltic pumping.

10. The floc strength was evaluated again (second such measurement).

11. The drainage time, pad moisture, and filtrate turbidity were evaluated as described earlier (first such set of measurements)

12. All of the filtrate, fiber pad material, and remaining fiber slurry from step 1 were recombined, placed in the blender, and sheared at the "blend" setting for 30 seconds.

13. Floc strength was measured for a third time.

14. Floc intensity was measured for a third time.

15. The drainage time, pad moisture, and filtrate turbidity were evaluated a second time.

16. The electrophoretic mobility was evaluated for the first time, using the final filtrate. 


\section{Results and Discussion}

\section{Preliminary Tests}

The optical floc intensity tests results appeared to be stable and reproducible without special handling of the samples beyond the description given in the previous section. Additional, preliminary tests also were carried out with the PDA 2000 low-gain device switched to the "Ratio" setting, as recommended by the manufacturer. Although this approach appeared to give meaningful output, several of the most highly flocced conditions caused the "Ratio" output to go off scale. Therefore, all of the data reported here were based on the "RMS" setting.

The rheometric floc strength tests proved to be sensitive to the presence of foam. The effect of foam was first noted when testing samples that had been treated with poly(DADMAC) and then subjected to high shear in a blender. Such foam was eliminated by dropwise addition of the minimum needed amount of dilute silicone-based defoamer Bubreak ${ }^{\circledR} 4428$.

\section{Blank Experiments}

Table 1 gives results of tests with replicate samples of from a master batch of untreated furnish. To guard against systematic errors, the blank experiments were spaced at even intervals over the project duration. The table shows the mean and standard deviation of each test through step 11 of the procedure given in the previous section. The second application of intense shear (step 12 of procedure) had no significant effect on the results corresponding to untreated furnish.

\section{Effects of Cationic Polyacrylamide Retention Aid}

As shown in Fig. 3, increasing addition of cationic polyacrylamide retention aid to the standard furnish yielded increasing values of the root-mean-squared (RMS) value of fluctuations in transmitted light intensity. The solid line in Fig. 3 corresponds to the first set of measurements when the slurry was pumped through the sensing head of the modified PDA 2000 apparatus, as described in the Experimental section. The dashed line corresponds to the same type of measurement after 30 seconds of pumping. It is evident that the peristaltic pumping had relatively little effect on the state of fiber flocculation in this case. Contrasting results were observed after treated slurry samples that had been exposed to 30 seconds of high shear in a blender. Those results are shown by the lower, dash-dot line in Fig. 3. It is apparent that blending was able to fully reverse the effect of the retention aid, relative to the described test.

The optical test results in the case of cationic polyacrylamide are consistent with a polyelectrolyte bridge model. As shown by Sikora and Stratton (1981), the macromolecular chains of retention aids are likely to break when a flocculated fibrous system is subjected to high shear forces.

The observation of total reversal of flocculation after blending, even at the highest levels of polymer treatment, does not necessarily follow from studies of the type reported by Britt and Unbehend (1976). Those authors found a residual effect of retention aid treatment, yielding higher fines retention when the highly sheared suspensions were tested under moderate levels of shear. The apparent disagreement can be explained in either of two ways. First, it is worth pointing out that the conditions of blending used in 
the present work were much more intense; Britt and Unbehend describe application of $1500 \mathrm{rpm}$ stirring only, which requires about 1 Watt of electrical energy. Approximately 500 times that rate of energy was consumed during the "blend" treatment in the present work. Second, the floc side evaluation was carried out under conditions of stirring that should tend to keep the fibers fluidized.

As shown in Fig. 4 increased treatment with cPAM progressively increased the output value of the viscometer test. It is worth noting, however, that more than half of the increase in viscometer output due to the additive was broken down when the furnish was passed through the peristaltic pump for 30 seconds. Treatment in the blender reduced floc strength to its original value prior to cPAM addition.

The contrast between the optical and viscometric data for cPAM treatment suggests that the two tests are sensing different aspects related to fiber flocculation and its reversibility. It is worth noting that the optical data and viscometric data differed most strongly when one considers the effects of peristaltic pumping. It appears that this intermediate hydrodynamic and mechanical shear regime was quite effective in reducing the network strength of flocs, but it did not reduce their size when evaluated by the optical method.

One hypothesis that may help explain this difference is related to the electrical potentials of the fiber surfaces. It is reasonable to expect that the cPAM on the surface of fibers reduced their absolute value of zeta potential, thus increasing the net colloidal forces of adhesion between them. Results shown in Fig. 5 are consistent with this hypothesis. As shown in the figure, the systems treated with cPAM were closer to neutrality. Alternatively, it is reasonable to assume that cPAM on fiber surfaces can have a residual ability to form polymeric bridging, though these bridges may be expected to be weaker than the original bridges (Sikora, Stratton 1981).

As shown in Fig. 6 increased treatment with cPAM accelerated the rate of "drainage" during vacuum filtration. However, almost all of the drainage-promoting effect was removed after the furnish had been subjected to intense hydrodynamic shear in the blender. The effect is consistent with either of two models. The first model assumes that flow of water around the outside of flocs is dominant. Such a model suggests that increased size and frequency of flocs should play the major role in promoting drainage rates. The second model assumes that the anchoring of fine particles onto fibers plays a dominant role. In other words, one assumes that the role of certain drainage-promoting chemicals is to prevent fiber fines from blocking channels in the wet web of paper as it is being formed (Gess 1989). It is worth noting that either one of these models is consistent with the data shown in Fig. 6.

As noted by Britt and Unbehend (1985) the fact that a chemical treatment promotes more rapid drainage on a forming fabric does not necessarily imply a lower moisture when the wet web leaves the forming section at the couch roll of a paper machine. Reasons for this behavior are summarized in much greater detail by Räisänen (1996). In light of the previous work it is not surprising that results in Fig. 7 showed little positive effect of drainage-aid treatments on the wet mass of the fiber pads after a standardized 30 seconds of vacuum application. Fiber pads formed after intense blending treatment of the flocced furnish tended to be wetter at the end of the vacuum dewatering cycle. Once again, this observation could be explained in terms of either model of how 
the cPAM treatment promotes drainage - either by promoting flocculation or by preventing fines from blocking drainage channels.

For further help in discriminating between the two models to explain the drainage-promoting effect of cPAM it is worth considering how the same treatment affected retention of fines. As shown in Fig. 8, increased cPAM addition sharply reduced the turbidity of filtrate collected according to the procedures given earlier. Surprisingly, the filtrate turbidity at each treatment level was essentially independent of whether the furnish had been subjected to high hydrodynamic shear after chemical treatment. When interpreting this data one needs to bear in mind that a majority of the observed turbidity signal is expected to come from the calcium carbonate filler. A relatively high turbidity (e.g. 280-330 nephelometric testing units) in the case of the untreated control is consistent with the existence of many unattached filler particles in the suspension. The fact that filtrate turbidity was a factor of ten lower after treatment, even after high shear exposure, suggests that most of the filler was associated with fibers and fiber fines capable of being filtered in by the screen and by the fiber mat itself. Because colloidal forces of adhesion appear to persist even after application of high shear, one almost has to rule out the "drainage channel" mechanism mentioned earlier. By default, the results then support the hypothesis that the main drainage-promoting effect of the cPAM in Fig. 6 was due to fiber flocculation and the ability of water to flow around the outsides of flocs under the conditions of testing.

\section{Effects of High-Charge Linear Polymer (DADMAC)}

As shown in Fig. 9, increasing treatment levels of the furnish with poly(DADMAC) increased the RMS light fluctuations up to a maximum, after which flocculation decreased. It is worth noting that the poly(DADMAC) sample corresponding to Fig. 9 had a molecular mass of about 1 million Daltons, which is very high relative to industry norms. Nevertheless, the results are consistent with electrostatic effects, rather than polymeric bridging. By looking at the values on the vertical axis of Fig. 9 it is clear that the increases in floc intensity caused by poly(DADMAC) were far less than those resulting from cPAM (compare Fig. 3). Another difference was the fact that application of high shear in the blender failed to reverse all of the effect of the cationic polymer. The data in Fig. 9 suggest that the high-shear treatment shifted the flocculation maximum to a higher polymer dosage. A possible explanation for such a shift is the known tendency of polyelectrolytes to penetrate into the fiber cell wall. Such penetration would reduce the effective concentration of the additive in the system.

Figure 10 shows how poly(DADMAC) treatment affected electrophoretic mobility values of file particles in the final filtrate after blending treatment. Because the point of zero charge roughly agrees with the point of maximum flocculation, these data are consistent with an electrostatic model of drainage promotion. In other words, the drainage-enhancing effect of the polymer can be attributed to colloidal forces of adhesion. It is well known that a condition of zero electrophoretic mobility corresponds to a minimum in electrostatic double-layer forces of repulsion between suspended matter, allowing the attractive London dispersion forces to bring particles together. During papermaking operations it is reasonable to expect that colloidal forces can promote drainage by mechanisms that include (a) promoting a more porous fiber mat structure, (b) causing microfibrils at the surface of fibers to line down, presenting more streamlined 
paths for water to flow around the fibers, and (c) helping to keep fines anchored to the fiber surfaces. Further work is needed to determine which of these possible mechanisms, or others, is most important.

In view of the fact that poly(DADMAC) clearly increased floc intensity, one would expect a corresponding increase in viscometer output. However, viscometric tests corresponding to those shown in Fig. 4 showed no significant increase in viscometer output due to poly(DADMAC). These observations suggest that a rather delicate balance is achievable - colloidal forces that are sufficient to achieve some level of "soft" flocculation but not so large as to hinder the subsequent redispersal of those same flocs by the kinds of forces present during papermaking operations.

Drainage effects of poly(DADMAC) were also determined. Unlike the results shown in Fig. 6 for cPAM, there was a maximum drainage rate. This maximum corresponded to treatment levels giving the maximum floc intensity. Unlike Fig. 6, the drainage benefits of the high-charge cationic polymer were not eliminated by high shear treatment. Indeed, the lowest drain time values were obtained after the treated slurries had been subjected to blending. Moisture of the fiber pads was consistently reduced after the poly(DADMAC) treatment. This result is in contrast to the lack of effect on pad moisture in the case of cPAM treatment. Notably, the reduction in pad moisture due to treatment with high-charge cationic polymer persisted even after application of high shear.

\section{Conclusions}

The two laboratory methods introduced in this report appear capable of giving insight into the mechanisms of retention and drainage chemical programs. Both methods required only modest changes to commercially available devices.

A key finding of the present study was that the floc size test and the floc strength test each appeared to give separate, complementary information. The optical test appeared to be sensitive to factors related to soft flocculation, including electrokinetic effects. By contrast, the rheometric test appeared to be sensitive only to the presence of flocculation resulting from treatment with very high molecular mass polymers, i.e. bridging flocculation. It is a defining feature of such flocculated structures that they tend to break down irreversibly when subjected to high levels of shear. Indeed, only in the case of the microparticle systems was there any detectable floc strength contribution remaining from chemical treatment, after the furnish had been exposed to high shear in a blender.

Results related to retention efficiency lend support to a strategy that is already used by many papermakers, as they continually look for ways to keep fine particles in their product, while still achieving a uniform distribution of fibers. That strategy involves treatment of the furnish with a flocculating polymer, then allowing it to pass through unit operations in the paper machine system that cause the fibers to become redispersed from each other. At the same time, as suggested by the present results, bonds between fibers and filler particles can remain intact after the high-shear treatment. Though this explanation is consistent with both the data and various theories cited, one still cannot rule out the possibility that filler particles and other fines were deposited again onto fiber surfaces immediately after the blending treatment was stopped. 
Results related to drainage rates lend support to the central importance of electrokinetic factors. From a papermaker's perspective, this is a fortunate consequence. It means that factors related to soft flocculation offer the key to drainage promotion. By definition, soft flocs are capable of being broken down by moderate forces. Such forces are already present on modern paper machines, and the papermaker has some control over these forces in areas that include jet impingement angle, wet-to-wire speed differences, hydrofoil adjustments, and two-sided dewatering strategies in the forming section.

\section{Literature}

Andersson, K. and Lindgren, E. (1996): Important properties of colloidal silica in microparticulate systems, Nordic Pulp Paper Res. J. 11(1), 15.

Andersson, S. R., Ringnér, J., and Rasmuson, A. (1999): The network strength of non-flocculated fiber suspensions, Nordic Pulp Paper Research J. 14(1), 61.

Artama, M. and Nokelainen, J. (1997): Control of retention and ash, Paper Technol. 38(8), 33.

Beghello, L., Toivakka, M., and Eklund, D. (1996): A device for measuring fiber floc sizes in highly turbulent fiber suspensions, Nordic Pulp Paper Res. J. 11(4), 249.

Bennington, C. P. J., Kerekes, R. J., and Grace, J. R. (1990): The yield stress of fiber suspensions, Can. J. Chem. Eng. 68, 746.

Britt, K. W. (1973a): Retention of additives during sheet formation, Tappi 56(3), 83.

Britt, K. W. (1973b): Mechanisms of retention during paper formation, Tappi 56(10), 46.

Britt, K. W. and Unbehend, J. E. (1976): New methods for monitoring retention, Tappi 59(2), 67.

Clémonçon, I. and Gerli, A. (1999): The effect of flocculant/microparticles retention programs on floc properties, Nordic Pulp Paper Res. J. 14(1), 23.

Eisenlauer, J., Horn, D., Linhart, F., and Hemel, R. (1987): Fiber-optic flocculation sensor for on-line control of retention and drainage aids efficiency, Nordic Pulp Paper Res. J. 4(4), 132.

Farnwood, R. R., Dodson, C. T. J., and Lowen, R. R. (1993): Forming and formation of paper, Proc. $10^{\text {th }}$ Fund Res. Symp., Oxford, Sept. 1993, Vol. 1, 183. 
Forsberg, S. and Bentsson, M. (1990): The Dynamic Drainage Analyser, Proc. TAPPI Papermakers Conf., 239.

Forsberg, S., and Ström, G. (1994): The effect of contact time between cationic polymers and furnish on retention and drainage, J. Pulp Paper Sci. 20(3), J71.

Gess, J. M. (1984): A new drainage analysis system, Tappi J. 67(3), 70.

Gess, J. M. (1989): Introduction to the G/W drainage retention system, TAPPI Retention and Drainage Short Course Notes, 49.

Gregory, J. (1973): Rates of flocculation of latex particles by cationic polymers, J. Colloid Interface Sci. 42(2), 448.

Gregory, J. (1985): Turbidity fluctuations in flowing suspensions, J. Colloid Interface Sci. 105, 357.

Hedborg, F. and Lindström, T. (1996): Some aspects on the reversibility of flocculation of paper stocks, Nordic Pulp Paper Res. J. 11(4), 254.

Hubbe, M. A. (1985): Detachment of colloidal hydrous oxide spheres from flat solids exposed to flow. 2. Mechanism of release, Colloids Surf. 16(3-4), 249.

Hubbe, M. A. (1986): Retention and hydrodynamic shear, Tappi J. 69(8), 116.

Hubbe, M. A. (1987): Detachment of colloidal hydrous oxide spheres from flat solids exposed to flow. 4. Effects of polyelectrolytes, Colloids Surf. 25(2-4), 325.

Janex, M. L., Chaplain, V., Counord, J. L., and Audebert, R. (1997): Influence of adsorbed polymers on the removal of mineral particles from a planar surface, Colloid Polym. Sci. 275(4), 352.

Kaji, H. and Monna, K. (1991): Fractal analysis of flocculation in pulp suspension, Proc. TAPPI Internat. Paper Phys. Conf., Vol. 1, 291.

Kerekes, $\boldsymbol{R}$. J. (1995): Perspectives on Fibre Flocculation in Papermaking, Proc. 1995 Intl. Paper Physics Conf., 23.

Knudson, M. I. (1993): Bentonite in paper: the rest of the story, Proc. TAPPI Papermakers Conf., 141.

Krogerus, B. (1993): Dynamic flocculation studies on fiber fines and filler clay, Nordic Pulp Paper Res. J. 8(1), 135.

Lin, J. T., Schuster, M. A., Hobirk, R. A., and Schellhamer, A. J. (1994): 
Apparatus for simulating processing parameters and predicting variables in a papermaking operation including sequential pulsation, gravity and vacuum drainage, fines retention, and paper formation, U. S. Pat. 5,314,581.

Mason, S. G. (1954): Fiber motions and flocculation, Pulp Paper Mag. Can. 55(13), 96.

McKenzie, A. W. (1968): Structure and properties of paper. XVIII. The retention of wet-end additives, Appita 21(4), 104

Milliken, J. O. (1977): Spectrophotometric determination of fines retention using the dynamic retention/drainage jar, TAPPI Retention Drainage Short Course Notes, 55.

Mühle, K. (1987): The effect of mechanical forces on adhesive strength in bridging flocculation, Colloids Surf. 22(2-4), 249.

Nerelius, L, Norman, B., and Wahren, D. (1972): Measurement of flocculation characteristics by light reflection, Tappi 55(4), 574.

Pelton, $\boldsymbol{R}$. H. and Allen, L. H. (1984): Factors influencing the adhesion of polystyrene spheres attached to Pyrex by polyethyleneimine in aqueous solution, J. Colloid Interface Sci. 99(2), 387.

Petersen, D. E. (1994): Nuclear density consistency meter evaluation, Proc. TAPPI Proc. Control Symp., 9.

Preikschat, E. (1998): Iso-Torq - the next generation of rotating consistency transmitters, capable of being extracted at full process pressure, Proc. TAPPI/ISA Proc. Control Symp., Vancouver.

Raghem-Moayed, A., and Kuhn, D. C. S. (2000): Turbulent Flocculation Measurement, J. Pulp Paper Sci. 26(4), 163.

Räisänen, K., Karrila, S., and Paulapuro, $\boldsymbol{H}$. (1994): The effects of retention aids, drainage conditions, and pretreatment of slurry on high vacuum dewatering, a laboratory study, Proc. TAPPI Papermakers Conf., 463.

Räisänen, K. (1996): High-vacuum dewatering on a paper machine wire section - a literature review, Paperi Puu 78(3), 113.

Rantala, T., Tarhonen, P., and Koivo, H. N. (1994): Control of paper machine wire retention, Tappi. J. 77(12), 125.

Sampson, $\boldsymbol{W}$. $\boldsymbol{W}$. (1997): The interdependence of sheet structure and drainage, Paper Technol. 38(8), 45. 
Sikora, M. D., and Stratton, R. A. (1981): The shear stability of flocculated colloids, Tappi 64(11), 97.

Sweger, $\boldsymbol{R}$. W. (1996): Novel drainage analysis of chemical additives in systems with increasing mill closure, Proc. TAPPI Papermakers Conf., 59.

Swerin, A., Glad-Nordmark, G., and Ödberg, L. (1997a): Adsorption and flocculation in suspensions by two cationic polymers - simultaneous and sequential addition, J. Pulp Paper Sci. 23(8), J389.

Swerin, A. and Ödberg, L. (1993b): Flocculation and floc strength in suspensions flocculated by retention aids, Nordic Pulp Paper Res. J. 8(1), 141.

Swerin, A., Powell, R. L., and Ödberg, L. (1992): Linear and nonlinear dynamic viscoelasticity of pulp suspensions, Nordic Pulp Paper Res. J. 7(3), 126.

Swerin, A., Risinger, G., and Ödberg, L. (1997b): Flocculation in suspensions of microcrystalline cellulose by microparticle retention aid systems, J. Pulp Paper Sci. 23(8), J374.

Swerin, A., Sjödin, U., and Ödberg, L. (1993a): Flocculation of cellulosic fibre suspensions by model microparticle retention aid systems, Nordic Pulp Paper Res. J. 8(4), 389.

Tam Doo, P. A., Kerekes, R. J., and Pelton, R. H. (1984): Estimates of maximum hydrodynamic shear stress on fiber surfaces in papermaking, J. Pulp Paper Sci. 10(4), J80.

Tanaka, H., Swerin, A., and Ödberg, L. (1993): Transfer of cationic retention aid from fibers to fine particles and cleavage of polymer chains under wet-end papermaking conditions, Tappi J. 76(5), 157.

Unbehend, J. E. (1976): Mechanisms of "soft" and "hard" floc formation in dynamic retention measurement, Tappi 59(10), 74.

Wågberg, L. (1985): A device for measuring the kinetics of flocculation following polymer addition in turbulent fiber suspensions, Svensk Papperstidn. 88(6), R48.

Wågberg, L., Björklund, M., Asell, I., and Swerin, A. (1996): On the mechanism of flocculation by microparticle retention-aid systems, Tappi J. 79(6), 157.

Wågberg, L. and Lindström, T. (1987): Some fundamental aspects of dual component retention aid systems, Nordic Pulp Paper Res. J. 4(2), 49. 
Wall, S., Samuelsson, P., Degerman, G., Skoglund, $P$., and Samuelsson, A. (1992): The kinetics of heteroflocculation in the system cationic starch and colloidal anionic silicic acid, J. Colloid Interf. Sci. 151(1), 178.

Yeung, A. K. C., and Pelton, $\boldsymbol{R}$. (1996): Micromechanics: a new approach to studying the strength and breakup of flocs, J. Colloid Interface Sci. 184(2), 579.

Table 1. Results of replicate experiments with untreated furnish

\begin{tabular}{|l|c|c|c|}
\hline & No. tests & Mean & $\begin{array}{c}\text { Standard } \\
\text { Deviation }\end{array}$ \\
\hline Floc strength index \#1 (rheometric) & 4 & 20.3 & 0.90 \\
\hline Floc size index \#1 (optical test) & 4 & 0.13 & 0.03 \\
\hline Floc size index \#2 & 4 & 0.14 & 0.03 \\
\hline Floc strength index \#2 & 4 & 20.2 & 0.83 \\
\hline Drainage time (s) & 4 & 35.8 & 3.0 \\
\hline Fiber pad wet mass (g) & 4 & 5.5 & 0.8 \\
\hline Filtrate turbidity (NTU) & 4 & 336 & 45 \\
\hline Electrophoretic mobility $\left(10^{8} \mathrm{x} \mathrm{m}^{2} / \mathrm{Vs}\right)$ & 2 & -1.66 & 0.14 \\
\hline
\end{tabular}




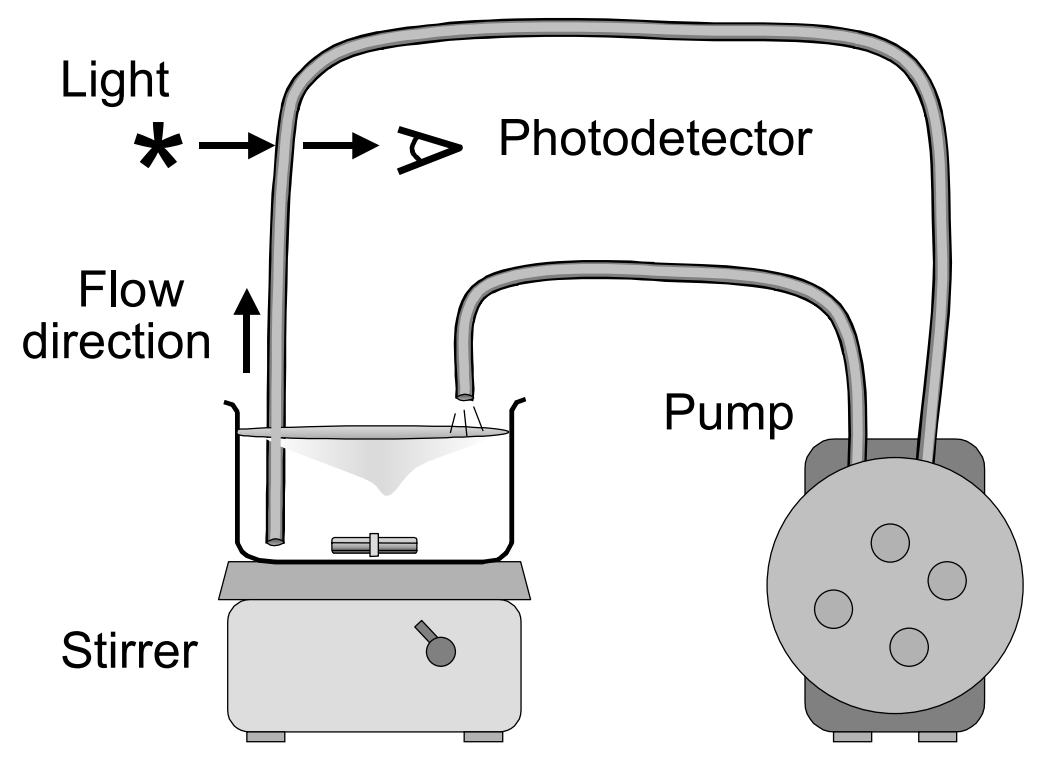

Fig. 1. Schematic diagram of system to evaluate intensity of fiber flocculation by measuring root-mean-squared fluctuations in light transmitted through a transparent, flexible tube.

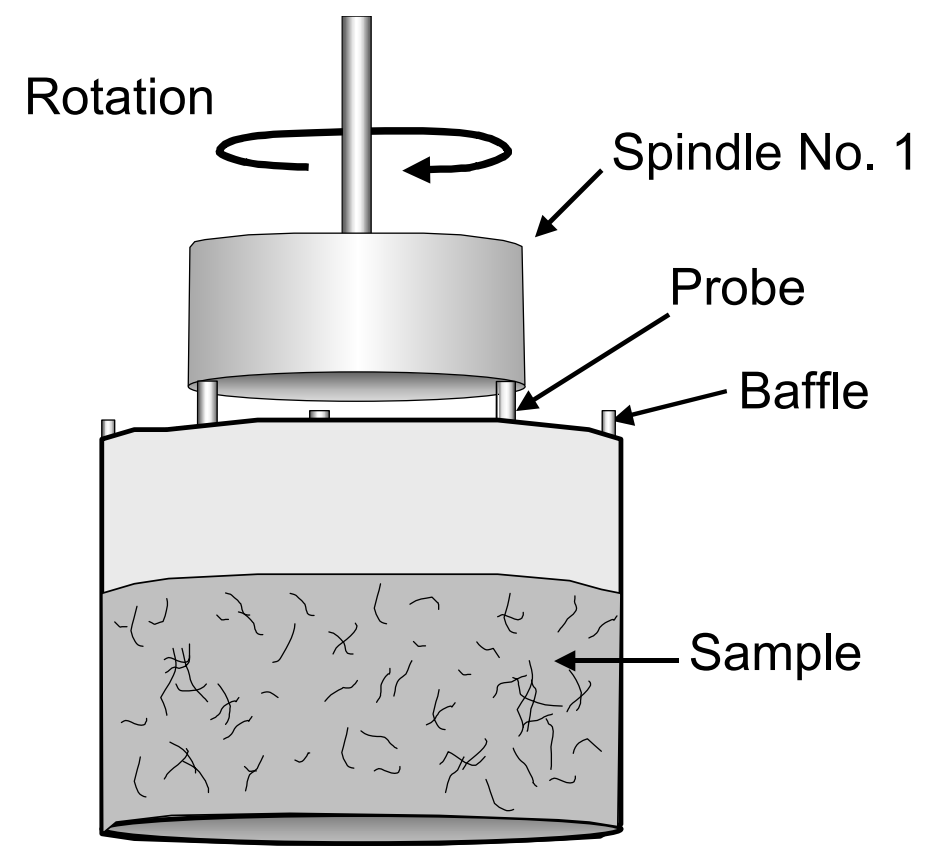

Fig. 2. Schematic diagram of apparatus used with Brookfield viscometer to evaluate the strength of fiber flocs by sensing the resistance to motion of cylindrical probes. 


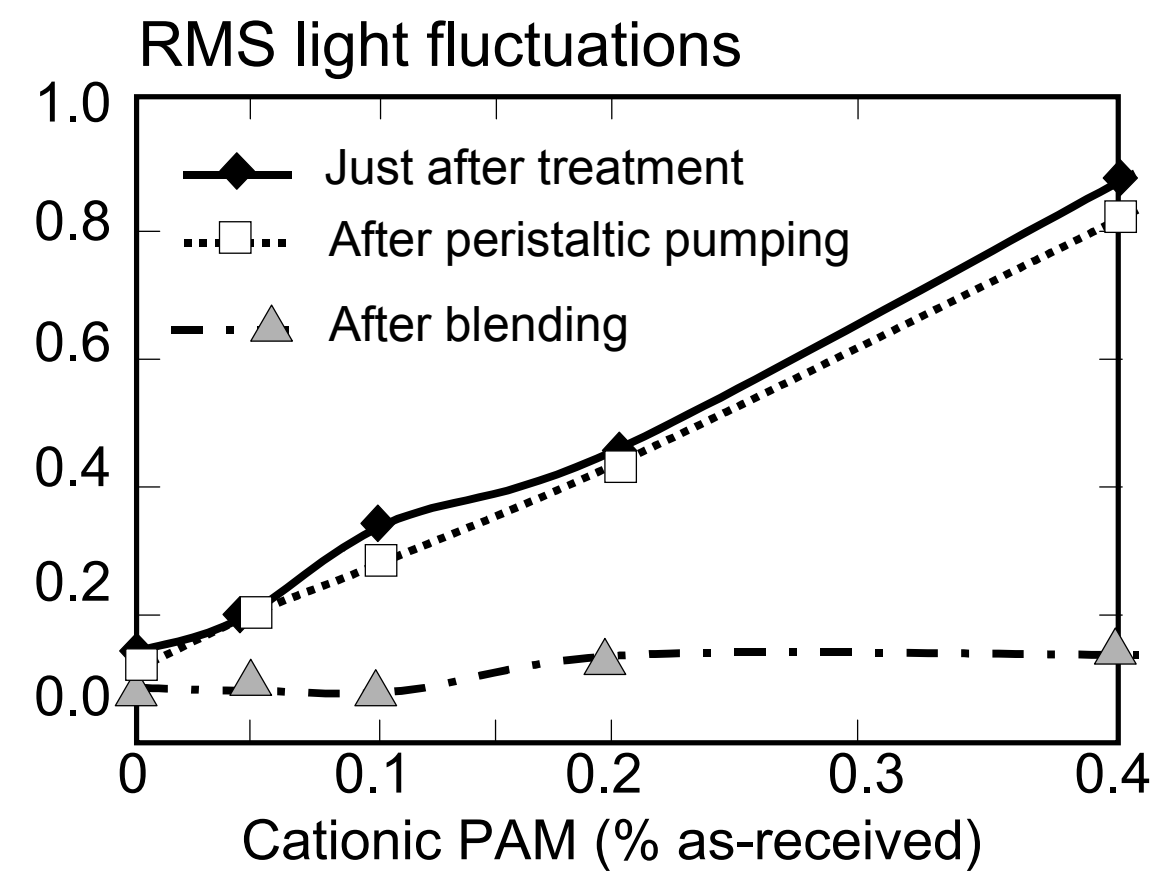

Fig. 3. Effect of cationic polyacrylamide (CPAM) addition on RMS output of PDA 2000 device. Results immediately after mixing were compared versus floc intensity after 30 seconds of peristaltic pumping, and after 30 seconds of blender agitation.

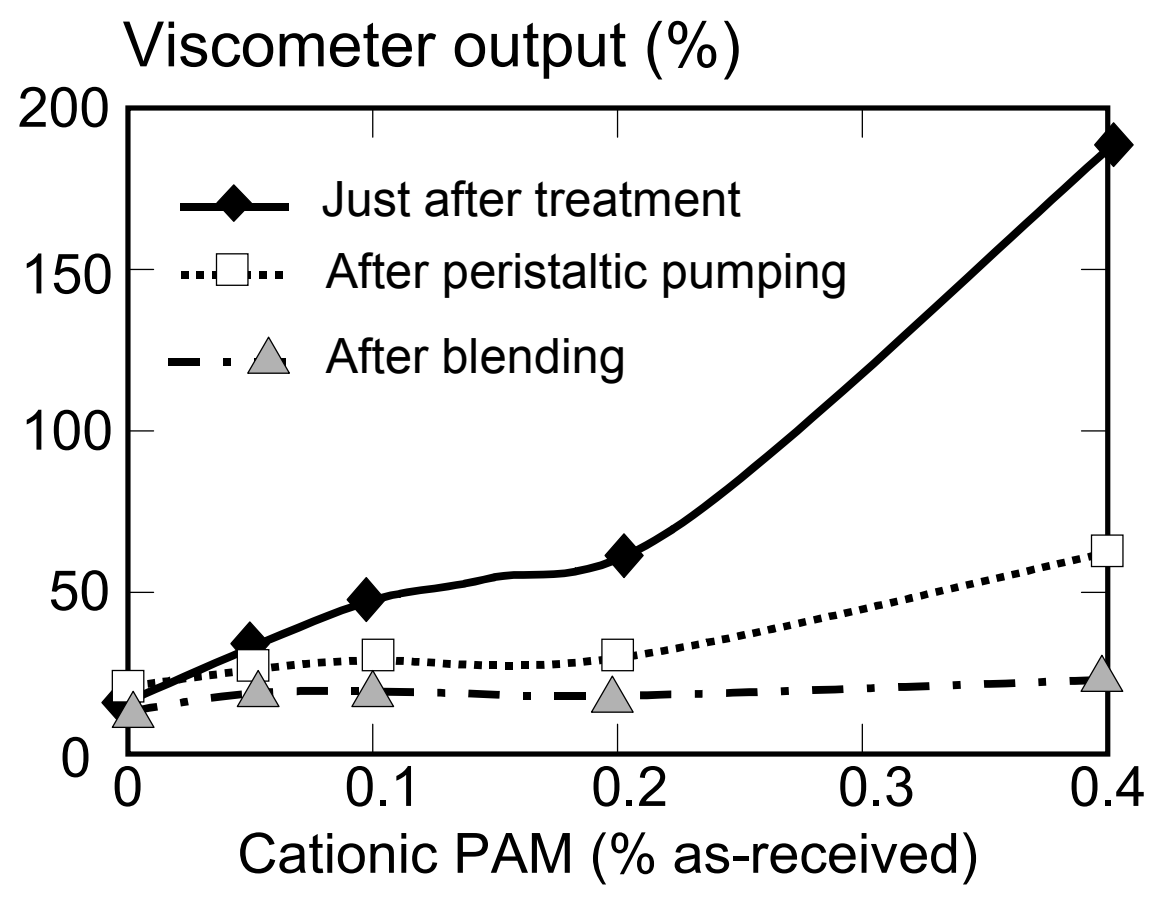


Fig. 4. Effect of cPAM addition on floc strength index

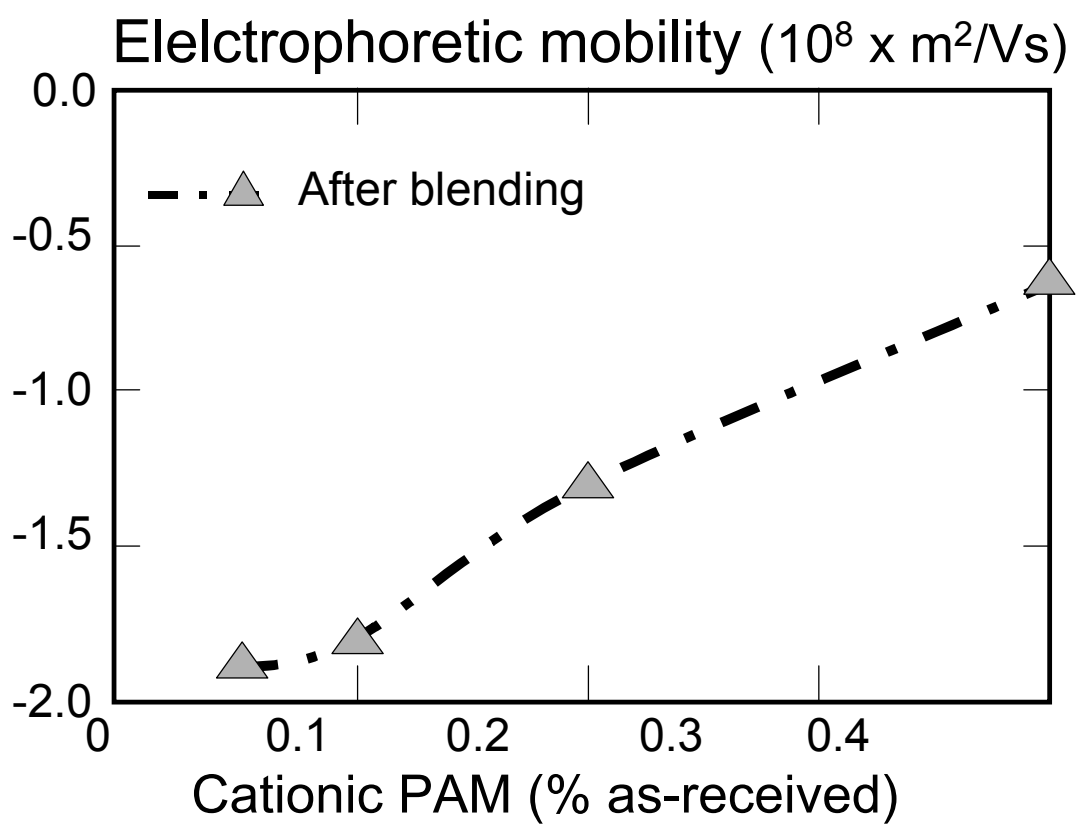

Fig. 5. Effect of CPAM addition on electrophoretic mobility of solids in the filtrate collected after shearing of the treated sample in a blender.

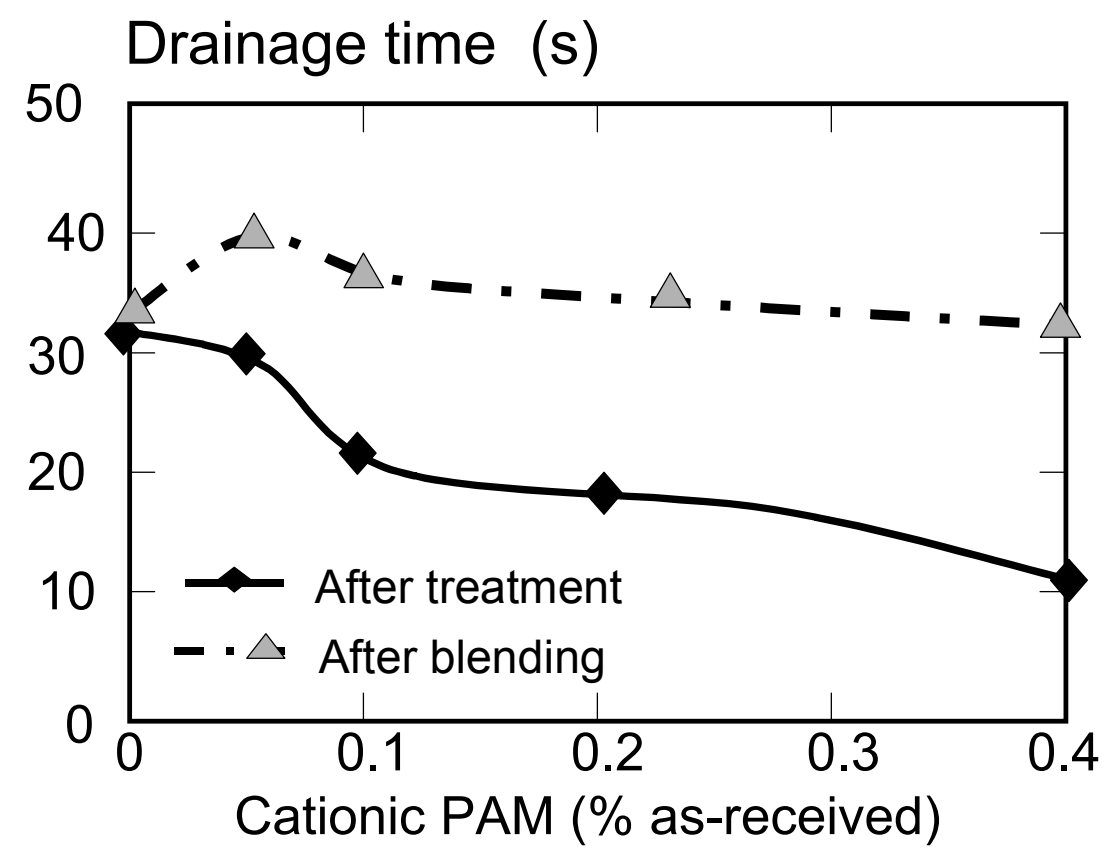

Fig. 6. Effect of CPAM addition on time required to drain $200 \mathrm{ml}$ of furnish through $42 \mathrm{~mm}$ diameter screen opening at 0.5 atmospheres of vacuum. 


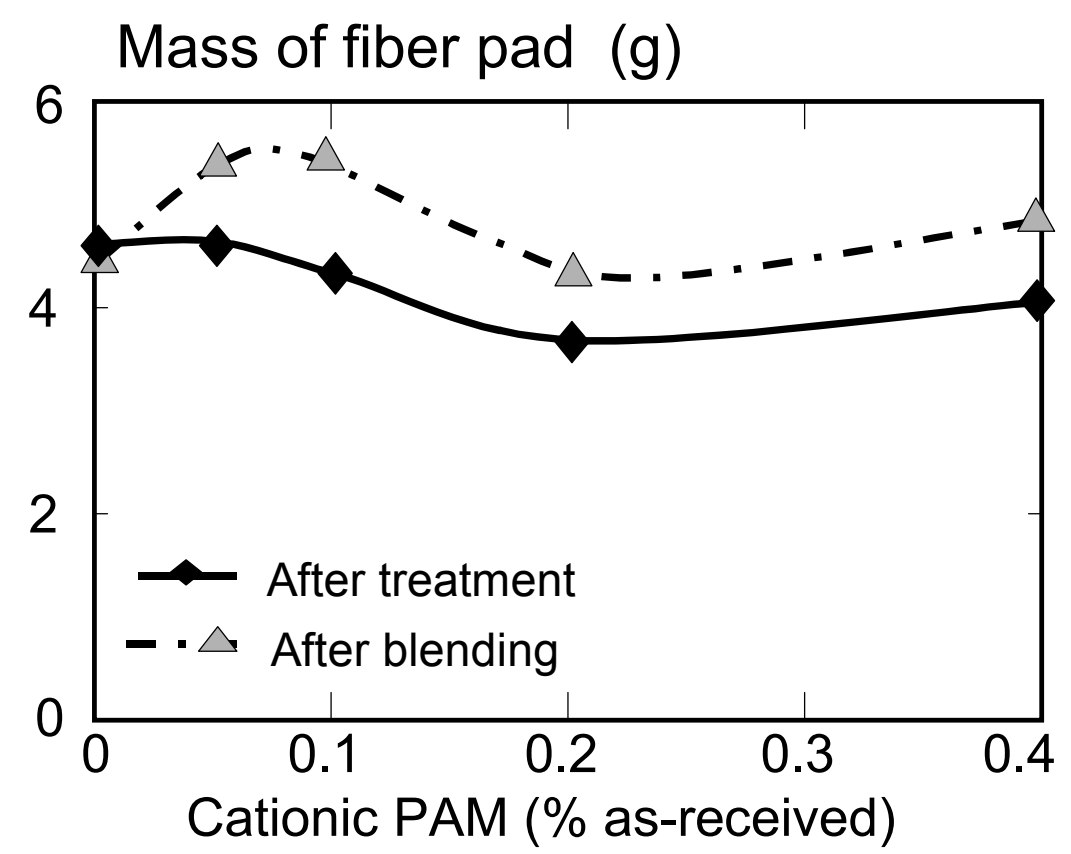

Fig. 7. Effect of CPAM addition on wet mass of fiber pad after 30 seconds of vacuum application. The corresponding dry fiber mass was $1 \mathrm{~g}$.

Filtrate turbidity (NTU)

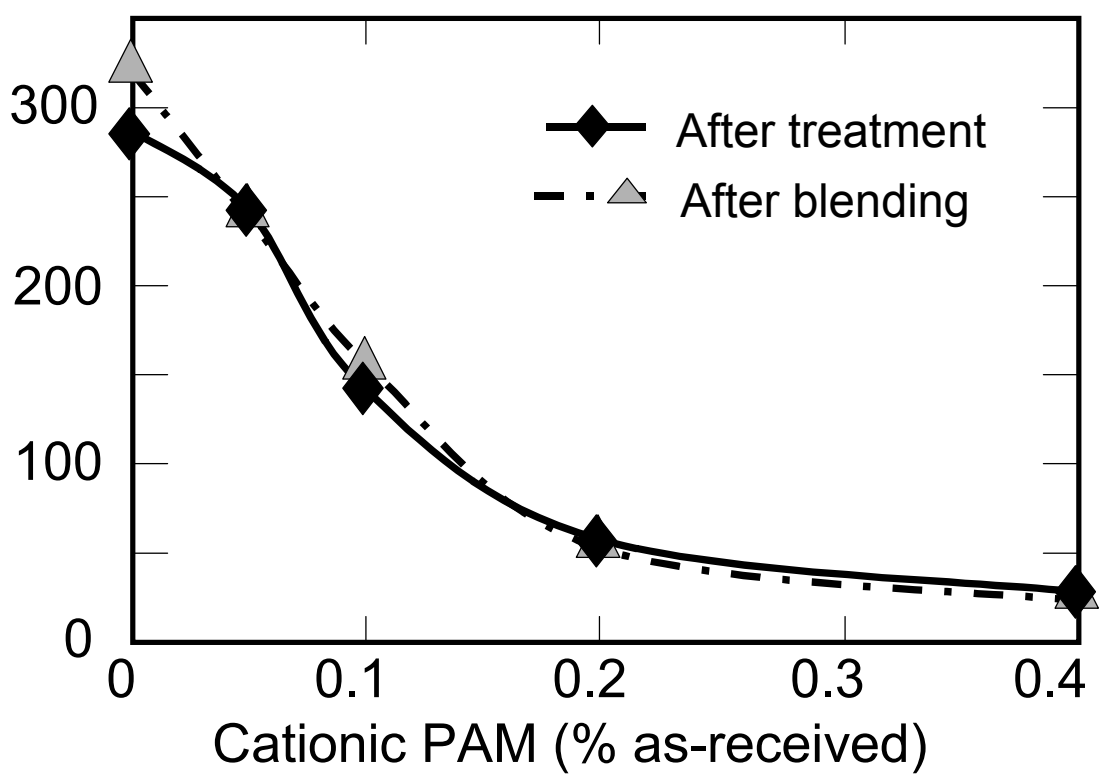

Fig. 8. Effect of CPAM addition to fiber slurry on turbidity of resulting filtrate 


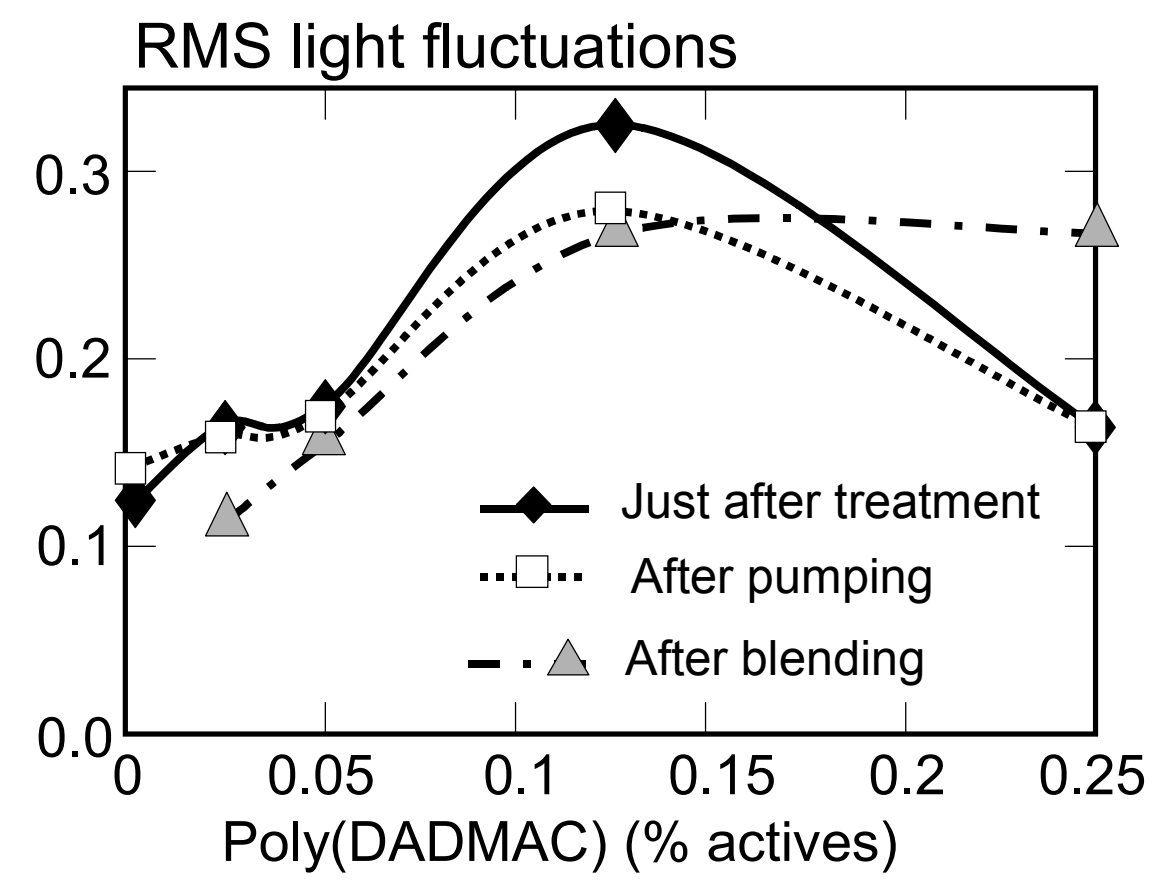

Fig. 9. Effect of high-mass poly(diallyldimethylammonium chloride) (DADMAC) on floc intensity

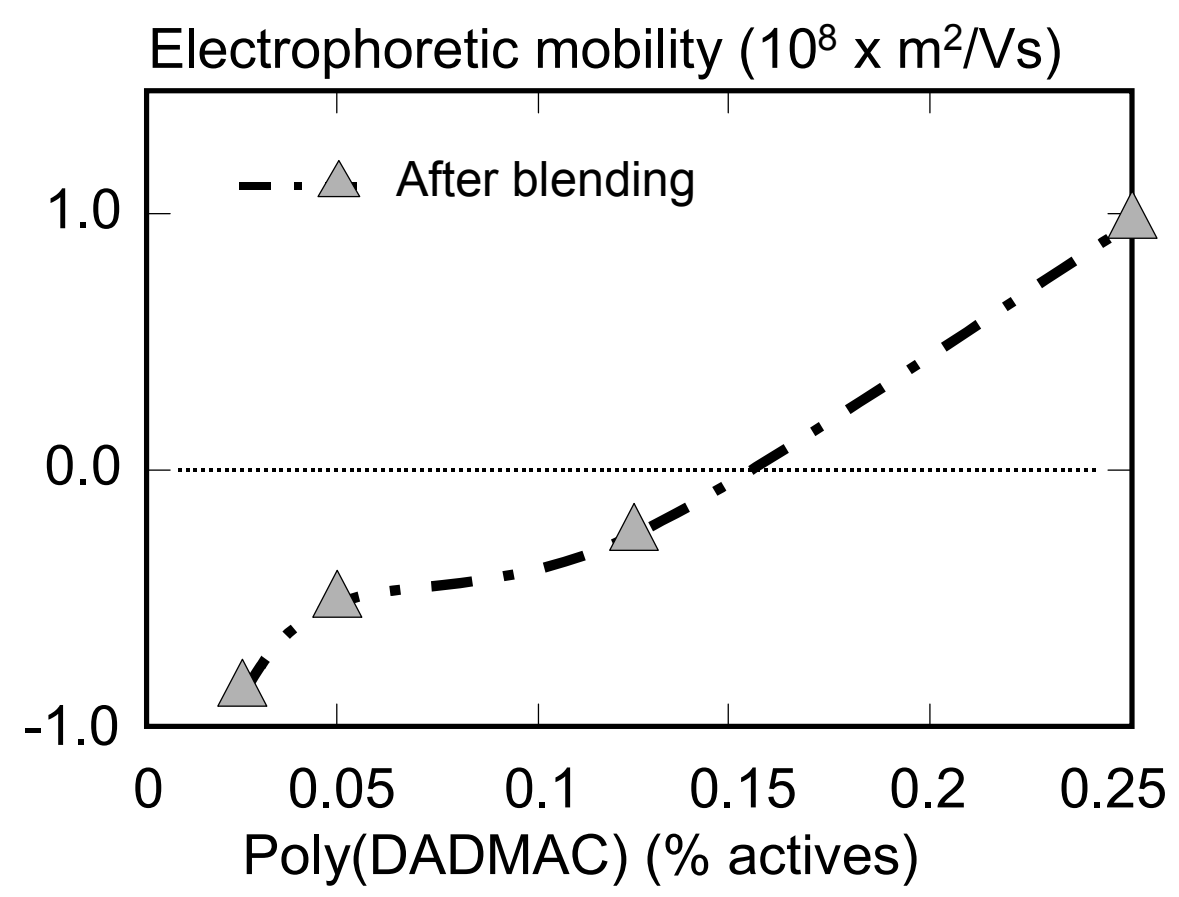

Fig. 10. Effect of high-mass poly(DADMAC) on electrophoretic mobility 